\title{
Hedging across genres: An approach for non- native students of English for Economics
}

\section{Catherine Resche}

\section{(2) OpenEdition \\ Journals}

Electronic version

URL: http://journals.openedition.org/asp/2193

DOI: $10.4000 /$ asp. 2193

ISBN: 978-2-8218-0382-4

ISSN: 2108-6354

Publisher

Groupe d'étude et de recherche en anglais de spécialité

Printed version

Date of publication: 31 December 2000

Number of pages: $289-308$

ISSN: 1246-8185

\section{Electronic reference}

Catherine Resche, "Hedging across genres: An approach for non-native students of English for

Economics », ASp [Online], 27-30 | 2000, Online since 17 February 2011, connection on 02 May 2019 URL : http://journals.openedition.org/asp/2193; DOI : 10.4000/asp.2193

This text was automatically generated on 2 May 2019.

Tous droits réservés 


\title{
Hedging across genres: An approach for non-native students of English for Economics
}

\author{
Catherine Resche
}

1 A preliminary word of caution is in order when dealing with English for Specific Purposes in general and English for Economics in particular. The risk is to consider that the phrase 'English for Economics' refers to a uniform set of specialised terms and phrases that can be used in any economic context. Such an oversimplification would not only evidence blindness to the language as such but it would give a very restrictive picture of the field by failing to take into consideration the various sub-fields and their own terminology, phraseology, conventions and constraints.

2 Though it is unthinkable to overlook the technical terms and phrases in the sphere of ESP, it is also essential to bear in mind that non-native students may be confronted with obstacles that can only be overcome by insisting on specific points of grammar and syntax on the one hand and by dealing with style and discourse on the other hand. Likewise, overlooking such notions as registers and genres (Couture 1986) is inconceivable if one seeks to give as accurate an account of the different instances of economic discourse as possible. A non-native public of students and potential researchers will, of course, encounter more difficulties when it comes to apprehending the subtleties of the language they will be required to use if they are to ever be accepted into a specific discourse community in their field of study. As underlined by Swales (1990: 10):

It is worth remembering that in the average world of English as a second language, the highest expectation of an instructional program is to raise the level of the students' language proficiency to somewhere fairly close to that of an average native speaker, however we might attempt to define such a person. Native-speaker competence is a point of arrival.

Language proficiency, of course, is not restricted to speaking but also involves writing. The particular aspect of discourse which is at the core of our preoccupations in this paper, i.e. hedging, deserves special attention when foreign language acquisition is at stake. Our choice was influenced by our wish to equip non-native students with the 
proper tools to reach a new stage of fluency and a higher degree of familiarity with a variety of widely-used hedging devices in English for Economics. We will argue that raising their awareness of such hedges will make reading and understanding easier. It is a first step towards helping them to become active users of hedges themselves. Ultimately, we wish to bring our contribution to transforming what can be viewed as a problem into a resource for non-native speakers (Skelton 1985: 41).

Our corpus was compiled with the needs of such a student public in mind. Accordingly, we took into consideration a range of genres students are bound to encounter in the course of their studies and research, namely textbooks, research articles and books, as well as technical analyses and reports issued by such financial institutions as central or international banks. We examined three textbooks: Economics by Paul Samuelson and William Nordhaus (1998), Macroeconomics by Rudiger Dornbusch and Stanley Fisher (1988) and European Macroeconomics by Robert J. Barro and Vittorio Grilli (1994). These textbooks range from a general introduction to both macroeconomics and microeconomics to a more specific approach. As for research literature, we have made a point of considering both books and articles published in reviews. The two books we have studied are by Gary Becker (The Economic Approach to Human Behaviour, 1976) and William Niskanen ( Bureaucracy and Representative Government, 1971). The isolated articles (See Appendix 1 for the complete list) were written by researchers from American and British universities. The third genre to be examined is a selection of quarterly reports by the Bank for International Settlements (BIS) and by official statements and analyses released by the American Federal Reserve, especially through its chairman Mr Alan Greenspan (Appendix 2).

Our method consisted in reading the different sources thoroughly with a view to sifting through them for any hedging device. By confronting our results across genres, we were able to draw up lists from which different categories of hedging devices emerged, which made it possible for us to observe similarities and disparities. Before trying to analyse the different types of hedging devices used across genres, we shall first examine why and in what circumstances hedging is resorted to.

\section{Reasons for hedging}

6 When introducing hedging devices to economics students, it is worth taking advantage of the fact that they already know what hedging means, at least from an economic point of view. Indeed, in economics, hedging is synonymous with 'covering against risk', or 'limiting one's exposure', according to the well-known adage that 'one should not put all one's eggs in one basket'. Thus, in the world of finance, different techniques are used to offset potential losses. The parallel is easy to draw with the linguistic use of hedging in discourse as a means of protecting oneself against some kind of risk which we shall now try to identify and examine. For want of a precise definition for hedging, we shall consider risk avoidance as a working proposition for this approach.

7 It is to be noted that the various instances of discourse in our corpus are all 'preparedtext genres', which, as Swales (1990: 63) reminds us "vary also in the extent to which their producers are conventionally expected to consider their anticipated audiences and readership". It stands to reason that audiences and readership are not restricted to one specific genre, so, authors may very well address one particular category of readers as the 
official target public while keeping another category of readers at the back of their minds. For example, the authors of the textbooks we have reviewed are also well-known economists, active researchers and acclaimed professors of economics. Inevitably, when they write textbooks, though they obviously target a public of students, they cannot ignore their fellow professors and researchers whose opinions on the book will determine its future as widespread reading and teaching material on a number of campuses. Criticism could then come from different quarters: from students who might find the book too difficult to study, from the teaching community calling its pedagogical approach and value into question, and from a larger group of economists and researchers likely to disagree with its options and contents. Understandably, the discourse of economics textbooks is characterised by a wide range of hedging devices, a great many of which are meant to anticipate the above-mentioned negative reactions.

In the case of research articles or books that are not designed for a student public, the authors must keep their potential readers and would-be critics in mind. The community of fellow researchers and referees they are addressing expects them to comply with a number of norms and conventions. Therefore, they will be judged on their ability to meet specific criteria concerning both content and form. For example, establishing a niche, i.e., finding a gap in the existing literature in the field under review in order to justify one's own current research, implies distancing oneself from other researchers who have already investigated the field. In so doing, the author may be led to express disagreement or even criticism, which obviously requires diplomatic skills. No matter how different his approach may be, disagreement will need to be expressed in such a way as to show respect for fellow researchers: Hedging, in this case, can be seen as a technique to remain polite (Brown \& Levinson 1987, Myers 1989).

9 Apart from diplomacy and politeness, there are other reasons for researchers and academic authors to resort to hedges. They obviously wish to cover themselves against the risk of being criticised for being confused, for taking a biased view or for reaching hasty conclusions. It is therefore vital for them to guide the reader to understand their approaches, to justify the method that served as a basis for their analyses, to account for their sources, to qualify their results. As Salager-Meyer (1994) points out, the Discussion section of research articles reveals a higher percentage of hedges, which is understandable for two reasons. First, it is not conceivable to impose one's views and interpretation as infallible. In this respect, hedges help "to show the general academic community that one has the necessary humility in making claims" (Dudley-Evans 1994). Honesty also comes into play: not only is the author expected to give other researchers their due by clearly indicating his sources and references, but he should also know when to acknowledge his limited ability to bring explanations or answers to every question or phenomenon. The second reason is that, while observed facts can be stated in quite a straightforward manner, their explanation, on the contrary, requires qualification. It is important for the authors to show that they have carefully considered alternative interpretations (Selinker 1979). Besides, incomplete or inconclusive data may prompt them to limit the scope of their findings temporarily and to wait until further evidence can be brought to support their pronouncements.

The same cautious approach can be observed in the third genre under review, i.e., the discourse of technical analysis from banking and financial authorities. In this case, the potential critics are politicians, fellow analysts and financiers, institutional investors and ultimately all economic agents, i.e., the public at large. Forecasting market reactions, 
consumer response, and the economy's future is a risky exercise. By definition, assessing the impact of past events and trying to make future projections based on current data available has little in common with a scientific, objective approach. A given situation may indeed evolve in different ways and it is important to make this clear to the public in one's analysis of the various possible developments. Distinctions should be established between short-term and long-term consequences. Otherwise, the financial authorities' competence and credibility might be seriously questioned. Again, hedging is a means to qualify one's analysis or to soften unpleasant news: in many circumstances, there are winners and losers, both of whom may be among the readers. It is therefore essential to show consideration for the general public. Diplomacy is the rule if one wishes to avoid sending the wrong message. Besides, if discourse is used carefully and efficiently, it may be enough to 'talk the market into reacting'. For instance, a carefully-worded analysis of the economic situation by a central banker may in itself play the role of a pre-emptive strike and avoid more aggressive measures. Yet, both over-optimism and over-pessimism could prove risky. For these reasons, official discourse requires a layer of opaqueness beneath a veneer of transparency, which is achieved by means of hedging.

11 It appears from this brief investigation into the reasons that push authors to resort to hedging that, even though there may be variations, the three genres mentioned in this study are not strictly differentiated in their use of hedges. For this reason, we have chosen to avoid examining each genre in turn, which would have implied tedious repetitions. Rather, we have organised our next section on the various instruments used for hedging along different lines that reflect the increasing degree of difficulty for nonnative students of economics as regards identifying, understanding and eventually reusing hedging devices in their own discourse. Accordingly, we first focus on metadiscursive expressions that send explicit signals to the reader. We then proceed from the periphery to the heart of economic discourse. Our next step will lead us to concentrate on the different parts of speech within the discourse of economics which can in turn become hedging devices, again moving from the most obvious to the least obvious ones. Finally, we investigate syntax as the hedging technique that seems to be most difficult to apprehend for non-native students.

\section{Different types of hedges}

\subsection{Hedging through metadiscourse}

Metadiscourse consists of comments to guide the reader through the text (1) (2), to warn him against possible misunderstandings (3) (4) (5), to refer him to former explanations (6), etc. This form of hedging anticipates criticism concerning a lack of logic, of clarity, of accuracy. It might be tempting to consider that such comments are only characteristic of pedagogical discourse, yet, as the following examples show, they are not restricted to one genre and can be found in the research literature ${ }^{\circledR}$ and in official documents (BIS, Fed) as well:

(1) In order to isolate the effects of government expenditures, we shall find it convenient initially to neglect these substitution effects from taxes [...] We bring in more realistic types of taxes and transfers in the next chapter. (BarroGrilli 1994: 306) 
(2) Although the word 'crime' is used in the title to minimise terminological innovations, the analysis is intended to be sufficiently general to cover all violations, not just felonies - like murder, robbery, and assault, which receive so much newspaper coverage- but also tax evasion, the so-called white-collar crimes, and traffic and other violations. (Becker 1976: 40) ${ }^{\circledR}$

(3) Do not confuse average cost with marginal cost -it's an easy mistake to make (Samuelson-Nordhaus 1998:120)

(4) Economists often use the term 'equilibrium' to signify market clearing. But because the concept of an equilibrium has been used in so many different ways in the economics literature, its meaning has become unclear.[...] We shall avoid the terms equilibrium and disequilibrium in our discussion. (Barro-Grilli 1994: 86)

(5) We repeat that this assumption is one that is temporarily needed for the development of the analysis. (Dornbusch-Fisher 1988: 136) caution', 'Be warned' or when they insist on the need to qualify their statements (6) (7):

(6)We end this section by repeating a warning that is important enough for us to risk overstating. (Dornbusch-Fisher 1994: 273)

(7) Our statement [...] is correct with two qualifications (Dornbusch-Fisher 1994: 43)

Hedging through metadiscourse is also a means of justifying one's approach to a problem - or of announcing that a particular point will be developed further in a following section or chapter (8) -, which can be achieved in various ways. In example (9), the authors clearly state their goal in case they should be criticised for overlooking some theoretical aspects of the problem:

(8) The consequence of relaxing this assumption will be explored in chapter 14 (Niskanen 1971: 45) ${ }^{\oplus}$

(9) We sidestep the theory of money supply in this and the next chapter and look only at the consequences for inflation and other variables of a given unexplained- time path of money. This type of analysis is crucial for an understanding of inflation, although it does not constitute a full study of the topic. (Barro-Grilli 1994: 141)

\section{excuses to account for the limited horizon in their explanation or discussion:}

(10) Space is too limited to do more than summarise the main implications of the theory... (Becker 1976: 108)

(11) This is not the place to examine in detail what triggered the initial problems in Asian financial markets and why the subsequent deterioration has been so extreme. I covered that subject recently before several committees of the Congress. Rather, I shall confine my discussion to the likely consequences of the Asian crisis for demand and inflation in the United States. (Greenspan 1998a: 4) (Fed)

16

Authors can also protect themselves against potential attacks against their analyses or conclusions by insisting that there are several possible interpretations (12):

(12) Of course, the results do not rule out an alternative interpretation [...] These large estimates call for further examination. One possibility is that [...] another is that [...](Boisso-Ferrantino 1997: 475,479) ${ }^{\circledR}$ 
Referring to analytical conventions, as is the case in (13) or insisting on the existence of a large consensus (14) can offer guarantees of credibility and seriousness:

(13) The approach taken here follows the economists' usual analysis of choice... (Becker 1976: 46)

(14) In recent years, as a number of analysts have pointed out, a significant shortfall has emerged in the private saving with which to finance domestic investment in plant and equipment and houses (Greenspan 1999b: 5)

Reliability can also be achieved by bringing evidence (15) to support the viewpoints that are being expressed or by referring to the past, which offers the author an obvious safeguard. Allusions to history in one form or another - 'History teaches us that...', 'History counsels us...'- are one of Alan Greenspan's favourite phrases (16):

(15) Looking at historical trends, the best evidence suggests that [...] (Samuelson-Nordhaus 1998: 652)

(16) As history counsels, it is unwise to count on any string of good fortune to continue indefinitely (Greenspan 1998a: 7) (Fed)

In many cases, simplification will be presented as a necessary starting point for an explanation and attention will clearly be drawn to this fact. Thus, neither the student who has been warned, nor the fellow researcher will find any reason to complain about being misguided or taken by surprise (17) (18):

(17) To demonstrate the different ways of measuring GDP, we begin by considering an oversimplified world in which there is no government, foreign trade, or investment. [...] Our first example is oversimplified to show the basic ideas. In the realistic examples that follow, we will add investment, government and the foreign sector.(Samuelson-Nordhaus 1998: 392)

(18) Because relative production costs are what matter in this model, the presentation is simplified by assuming that the foreign firm incurs zero marginal costs for the production of both goods. (Hartigan 1995:446) ${ }^{\circledR}$

As is pointed out in (18), simplifying means relying on models and resorting to speculative examples. Obviously, the numerous hypothetical examples which aim at 'exploring what could have or could not have occurred in the real world (Bondi-Paganelli 1996: 34) require more caution with a student public and have been underlined by many linguists concerned with economics textbooks (Tadros 1985, Henderson \& Hewings 1987, Hewings 1990) as potentially confusing. The risk indeed, is for the readers to fail to realise or to remember that the author is dealing with an unreal, theoretical world and to mistake it for the world of facts (Myers 1992). Apparently, the authors of the more recent economics textbooks in our corpus are aware of this risk and make a point of regularly reminding the reader that reasoning in economics is based on hypothetical considerations (19) (20) (21) (22):

(19) In the real world, however, no economy actually conforms totally to the idealised world of the smoothly functioning invisible hand. (SamuelsonNordhaus 1998: 34)

(20) Notice that throughout this analysis we assumed a 'perfect' world credit market, where the interest rate was the same for each country. (Barro-Grilli 1994: 124)

(21) As an extreme and unrealistic example, one could imagine the economy producing exactly the same output in two years, between which all prices 
have doubled. The hypothetical outputs and prices of bananas and oranges... (Dornbusch-Fischer 1988: 34)

(22) The idyllic scenario of full adjustment to inflation drawn here does not describe economies that we know. (Dornbusch-Fischer 1988: 563)

21 As in examples (20) and (21), verbs like 'assume', 'imagine', are also widely used. So are ' recall', or 'consider', which very often enable the author to address the reader directly (23). This amounts to calling upon him to accept and respect the 'rules of the game' and thus to make him aware that he is entering a hypothetical world:

(23) Consider a two-country world. Assume that the home country and the foreign country are identical in size... (Lane 1996: 501) ${ }^{\circledR}$

Yet, in spite of these noticeable efforts, ambiguity has not completely disappeared and some of the hedging devices, when combined, may prevent the reader from clearly distinguishing between the real world and the world of hypothesis. In examples (24) and (25), such words as 'concrete' and 'realistically' could justifiably be meant to describe reality, whereas they are used only to introduce assumed illustrations of the theory. Although we leave the realm of theory proper, we are not dealing with the real world either and, in this respect, both terms are inaccurate. Arguably, the verbs 'suppose', 'say', ' assume' and 'consider' should remind the reader of the hypothetical context. In addition, the situations described here are clearly unrealistic. Therefore, we are led to conclude that both 'concrete' and 'realistically' could have been done without:

(24) To make the problem concrete, consider a man who is paid, say, $\$ 1,800$ each month. Assume that he spends the $\$ 1,800$ evenly over the course of the month, at the rate of $\$ 60$ per day. (Dornbusch-Fischer 1988: 342)

(25) Suppose, realistically, that an individual did not know precisely what payments he would be receiving in the next few weeks and what payments he would have to make. (Dornbusch-Fischer 1988: 350)

In the past, textbooks were sometimes criticised for lacking references to the primary literature (Myers 1992) and their authors were blamed for failing to give the student public enough background information on the state of research. Their means of hedging against such criticism now consists in making ample use of references to schools of economics and theorists (26) (27), as well as to recent findings in the world of research. By stressing the relative, temporary character of some findings, they also teach the students to be humble in their conclusions (28) (29):

(26) As Adam Smith observed over two centuries ago, people tend to specialise with respect to occupations and production activities. (Barro-Grilli 1994: 49)

(27) We define monetarism by describing Friedman's views, but we should warn you that in so doing we over-emphasise Friedman's role in developing and sustaining monetarism. (Dornbusch-Fisher 1988: 666)

(28) Much of the analysis of this book would, in the past, have been considered monetarist [...]. If economists did not modify their analyses in the light of new theories and evidence, the field would be barren. (DornbuschFisher 1988: 672)

(29) Which of these theories best explains the facts of business cycles? Actually, each of the competing theories contains elements of truth, but none is universally valid in all times and places. The key to macroeconomics wisdom is to combine understanding of the different theories with 
knowledge of where and when to apply them. [...] Our experience has convinced us of the importance of keeping minds open to alternative points of view. Time and again in science, the orthodoxies of one period are overturned by new discoveries (Samuelson-Nordhaus 1998: 437, 620) that they are quite visibly signalled to the reader. In fact, they can be considered as comments at the margin of discourse or comments on discourse. Yet, as they abound in the literature, they are worth paying attention to, especially when dealing with a nonnative public that will one day be led to respect the same rules - if only to make reading and understanding easier initially. The terms or phrases we shall now focus on are included in the discourse of economics proper, even though they may not be strictly limited to it. Understandably, they will only be examples taken from longer lists which can be found in Appendix 3.

\section{2. Hedges within the discourse of economics}

25 As we have opted to progress from the most explicit to the least obvious means of hedging, we shall start this section with easily identifiable lexical items. A number of adjectives, verbs and adverbs or adverbial phrases are indeed available for any author wishing to use them not only as 'shields' (Rounds 1982) or umbrellas to protect themselves, and as softeners, sweeteners, or 'sugar-coating strategies' (Wills 1997: 45) to make their discourse more palatable, but also as props to support their arguments. Many are quite transparent in so far as they contain in themselves indications of probability, degrees of uncertainty and approximation, notions of conditions to be met, qualifications and restrictions. The difficulty for non-native students often lies in appreciating the varying nuances introduced by these items. This is an essential step for them to be able to decode what they read properly. The second stage will be for them to decide when and where to insert the various hedges in their own discourse. Borrowing from Samuelson and Nordhaus's context in (29), we could suggest that 'the key to hedging is to combine understanding of the different forms available with knowledge of where and when to apply them'.

\subsubsection{Adjectives}

We shall start with adjectives that are easily identifiable by non-native students who should not need much training to re-use them. The most visible adjectives used as hedges -plausible, possible, impossible, probable, likely, unlikely- have already been examined in former studies (Dudley-Evans 1994:131). We shall therefore be satisfied with quoting a few typical phrases from our corpus like 'the most likely explanation' (Barro-Grilli 1994: 312), 'a plausible description' (Dornbusch-Fischer 1988: 754) or 'the most general possible definition’ (Niskanen 1971: 20) ${ }^{\circledR}$. A number of other, less obvious adjectives, however, are worth underlining for two reasons. One is that they might not come naturally to the nonnative student's mind and the other is that, instead of acting as softeners, these adjectives are used for strengthening, reinforcing the words they modify. Such adjectives should also become a resource to insist, for example, that one's findings are consistent with a given well-known theory, or supported by ample evidence. In other circumstances, adjectives like 'partial' in 'a partial explanation' or 'according to partial data' (BIS 1999: 22), will be very useful to indicate that discussion is left open to further developments. 
Cautious, purposeful vagueness will be achieved through the use of another type of adjectives as in example (30):

(30) The three indicators in Table 2.1 provide rough estimates of the relative magnitude of the economic activities of bureaux. (Niskanen 1971: 16-17) ${ }^{\oplus}$

When it comes to expressing polite criticism of fellow researchers' arguments and to questioning their findings, it may be helpful to be familiar with such adjectives as " inconclusive', 'limited', 'marginal'or 'weak'. One last adjective worth mentioning for its ability to be used in various compounds is 'near'. It represents a very economical way of qualifying a statement, provided one becomes aware of the opportunities its flexibility offers (31):

(31) The fact that most major equity indices returned to near-peak levels in December suggests that the systemic repercussions of the upheaval were contained. [...] There was a near-halving of facilities arranged for emerging market names. (BIS March 1999: 3, 5)

What is interesting in these few examples, as Salager-Meyer (1994) pointed out, is that words that were not specifically designed to be hedges can be used for the purpose of hedging.

\subsubsection{Adverbs}

In this category, we obviously find the adverbs corresponding to some of the adjectives mentioned in the former section, as illustrated by 'probably' or 'possibly'. While the former is quite transparent and easy to use, interpreting and re-using the latter may not be as simple as it may seem at first for a non-native student. Indeed, it will be necessary to establish a distinction between the different possible meanings of this adverb. As a hedge, it is synonymous with 'perhaps', but in some contexts, for example in questions, it may indicate that one is surprised or even shocked. With a negative, it can also refer to someone's unwillingness or inability to do something. It will therefore be worth warning the students against possible misunderstandings. As for 'approximately' or 'roughly' which also echo corresponding adjectives, they are logically found in contexts involving numbers, figures or percentages. They are used either where exactness is impossible because the data are not available- or unnecessary. Whatever the reason, such 'approximators' (Rounds 1982) enable the author to insist on the fact that he is dealing with estimates. However, we would like to draw attention to other adverbs in this category, such as 'somewhat', 'considerably' or equivalent groups like 'to a certain / considerable extent' which do not modify numbers or figures, but help, nevertheless, to convey a degree of vagueness. 'Widely', in compounds such as 'a widely-known theory', 'a widely-used model', 'a widely-accepted assumption' appears to be a wonderful vehicle for bringing evidence to support one's views. We could also quote 'practically', 'almost', ' virtually' and 'hardly', which conveniently introduce qualifications, and should not escape the reader's notice.

30 Adverbs can be used as well for bringing in restrictions. In this respect, 'especially' deserves a word of caution because its use, again, depends very much on the context. In (32), for example, it helps to limit the scope of a remark, while in (33), it is meant both to insist on the adjective 'alert' which it modifies and to avoid using a stronger adverb such as 'extremely': 
(32) PPP is a plausible description of the trend behaviour of exchange rates, especially when inflation differentials between countries are large. (Dornbusch-Fisher 1994: 754)

(33) The Committee recognises that in the current dynamic environment, it must be especially alert to the emergence, or potential emergence, of inflationary forces that could undermine economic growth. (Press Release, June 30, 1999) (Fed)

Adverbial phrases can also contribute to limiting the scope of a remark or an analysis thus protecting their authors- by bringing indications of time as is the case with 'as yet', ' so far', or 'to date' (34):

(34) [...] the basic message is that inflation to date has remained low. So far this year, our economy has continued to enjoy a virtuous cycle... (Greenspan 1998b: 3) (Fed)

Another type of restriction is dictated by the need for economists and researchers to study the impact of a measure on a particular variable. In order to do so, they have to isolate it while the other elements in the hypothetical model remain unchanged. This is signalled to the reader by the now famous ceteris paribus or its various equivalents in English: 'all other things being equal', 'other things held constant', etc. Lastly, adverbs offer authors a means of protecting themselves against attacks from critics by distancing themselves from their remarks. By hiding behind an anonymous source thanks to an adverb such as reportedly, they indicate that they are only echoing someone else's conclusions. They can also anticipate criticism by means of 'admittedly', 'arguably', ' conceivably', 'surely', or 'presumably', not to mention 'seemingly' and 'apparently' which are easy safeguards as they suggest a personal impression or an initial approach that may of course be questioned and needs to be confirmed. As can be seen, adverbs account for a resourceful category in terms of hedging, providing non-native students have become proficient enough in their use.

\subsubsection{Verbs}

Here again, starting with the most obvious items, we cannot omit verbs such as 'appear to', 'seem to', 'tend to', which serve to introduce and modify other verbs by softening their impact (35):

(35) Independent data on costs and prices in recent years tend to confirm what aggregate data on output and hours worked indicate: that productivity growth has risen. (Greenspan 1999b: 4) (Fed)

There would be no need to deal at length with this category of widely-used hedges if it were not for the potential misunderstandings that 'appear to' might create for a nonnative student if he is not trained to distinguish between different contexts. For example, in context (36), the term underlines the gap between appearance and reality and draws attention to the danger of a hasty conclusion. At other times, however, it may be synonymous with 'it is apparent', 'it is obvious', or 'it turns out to be...' as in example (37). And, of course, it may be a means of avoiding blunt statements and thus protecting oneself, in which case we can speak of hedging (38): 
(36) The policies needed to prevent the fluctuations in unemployment [...] appear to be simple. But if it is all so simple, how did the fluctuations occur? The answer must be that policymaking is far from simple. (Dornbusch-Fisher 1994: 415)

(37) The real world appears not to be classical (Dornbusch-Fischer 1988: 244)

(38) The US dollar and sterling appear to have benefited from the turmoil, with issuance in these two currencies rising by $5 \%$ and $56 \%$ respectively. (BIS 1999:19)

In spite of the precise percentages quoted in (38), the view expressed by the BIS needs to be qualified - hence the use of 'appear to' - simply because causality is always difficult to establish with certainty.

If we refer to (35) again, we can notice a second verb used as a hedge, namely 'indicate'. It belongs to another series of verbs - like 'imply', 'suggest', 'attempt to', 'try to', which nonnative students should find easy to identify and re-use: They all aim at introducing cautious analyses or conclusions. What is striking, and has been evidenced in our corpus, is the frequent coupling of some of these verbs into longer hedges such as 'tend to appear', 'seem to indicate', 'seem to imply', or any other combination (39):

(39) Recent experience does seem to suggest that the economy has become less inflation prone than in the past... (Greenspan 1999a: 5) (Fed)

These pairs are recurrent enough to have been referred to as 'fertilised hedges' (Banks 1995: 8) or 'compound hedges' (Dudley-Evans 1994: 131). The phenomenon is not restricted to one kind of verb and can also include adjectives as well as adverbial phrases as illustrated by contexts (40) and (41):

(40) We think that it is plausible to assume that [...] (Becker 1976: 197) ${ }^{\circledR}$

(41) In those circumstances, and barring other considerations, a reduction in the rate of population growth appears to be a way of achieving higher levels of steady state per capita income and thus an escape from poverty. (DornbuschFisher 1988: 728)

Such a multiplication of hedging devices can be observed at the level of a sentence, a group of sentences (42) (43), and even a paragraph. Hedges then can be said to grow into a 'thicket', which may paradoxically make understanding less easy and may be more difficult for non-native people to reproduce in their discourse:

(42) The statistical evidence does allow us to say something about the likely range of parameters and multipliers, so that at least we can get some idea if the type of errors that could result from a particular policy action. (Dornbusch-Fisher 1988: 449)

(43) Economists have long recognised a 'wealth effect' [...] though the magnitude of this effect remains difficult to estimate accurately. We have some evidence from recent years that all or most of the decline in the saving rate is accounted for by [...], which suggests that the wealth effect has been real and significant. Thus, all else equal, a flattening of stock prices would likely slow the growth of spending, and a decline in equity values, especially a severe one, could lead to a considerable weakening of consumer demand. (Greenspan 1999b: 3) (Fed) 


\subsection{Hedging through grammar and syntax}

39 In this last section, we would like to mention a number of points which non-native students cannot afford to overlook if they wish to be able to use a wider range of hedges. Space is too limited here to deal at great length with all the aspects of grammar involved, many of which have already received ample attention in the literature on the topic. If we just briefly mention the need for our target public to be able to use 'may', can', 'might', ' could' appropriately, it is precisely because our corpus abounds with sophisticated verbal phrases including such modals. They can be coupled with the passive form of a verb (44) or combined with past tenses meant to suggest cautious interpretations of earlier events (45):

(44) About $40 \%$ of the reported decline in total claims on Russia can be estimated to represent changes in the dollar price of defaulted Treasury bills and bonds denominated in roubles. (BIS 1999: 9-10)

(45) While collateralisation may have initially contributed to delaying the drying up of liquidity, it may have amplified the subsequent turnaround and the associated reduction in banks' credit exposure. (BIS 1999: 7)

Non-native students should develop their skills in using the passive which conveniently enables an author either to distance himself from the facts under review or to be vague enough as regards his sources (46):

(46) Concerns have been expressed that the recent proliferation of new eurodenominated contracts may be at the expense of liquidity. (BIS 1999: 26)

41 In this respect, for a non-native public, part of the difficulty lies in assessing when to resort to the passive and when to use the active with ' $r$ '. Indeed, though writing in one's own name may seem a very direct form of expression at first, it can also be meant as a hedge, especially in restrictive phrases like 'as far as I know', 'to my knowledge'. Understandably, in (47), the author anticipates counter-arguments by underlining that his information may be incomplete. In (48), he insists that his analysis is based on his own perception, which may well be different from anyone else's:

(47) In addition, a common generalisation by persons with judicial experience is that a change in the probability has a greater effect on the number of offences than a change in the punishment, although, as far as I can tell, none of the prominent theories shed any light on this relation. (Becker 1976: 46) ${ }^{\oplus}$

(48) The main contribution of this essay, as I see it, is to demonstrate that optimal policies to combat illegal behaviour are part of an optimal allocation of resources. (Becker 1976: 100) ${ }^{\circledR}$

In addition to being able to determine when to use the passive voice and when to opt for ' $I$ ', it is also useful for students to feel at ease with vague quantifiers such as 'some', 'little', ' few', etc.(49):

(49) To gauge the potential for similar, if not larger, gains in productivity going forward, we need to attempt to arrive at some understanding of what has occurred to date [...] There is little evidence that company executives or security analysts have significantly changed their views in recent months of 
the longer-term outlook for continued price containment, [...] (Greenspan 1999b: 2) (Fed) aspect of discourse is a real challenge in the field of second-language acquisition. Although, as we have seen, acquiring a number of lexical items - e.g., deficiency or shortcoming - may help to tone down one's criticism of an author's arguments, the art of sophisticated understatements cannot be mastered by learning rules and merely putting them into practice. It is important, however, to insist on such forms as in (52) whenever possible and to analyse them, if only to train the students to identify and apprehend them:

(52) We believe the evidence to date is on balance unfavourable to the Barro-Ricardo proposition, but recognise that the issue has not yet been decisively settled. (Dornbusch-Fisher 1988: 605)

Another interesting feature which should be drawn to their attention consists in avoiding altogether negative-sounding terms - such as inadequate - when expressing negative judgements, preferring not... adequate as in example (53). Likewise, when an author wishes to suggest that his findings are supported by evidence, he will refrain from using too 
positive a term like consistent with which might betray too much self-confidence. Rather, he will prefer to tone down his comment by means of not inconsistent (54):

(53) Market participants themselves recognise that current risk management systems have not been adequate in identifying the risks and potential losses stemming from the recent turbulence. (BIS 1999: 4)

(54) The findings, in fact, are not inconsistent with divergence within ASEAN.

(Karras, 1997: 429) ${ }^{\circledR}$

Undoubtedly, it would be unrealistic to expect non-native students to make full use of all the subtleties offered by what remains a foreign language for them. It is important, however, to raise their awareness of various widely-used hedging devices -an aspect which is still too often neglected in the field of second-language acquisition.

\section{Conclusion}

This paper was initially intended as a guided tour of the most usual hedging devices likely to be encountered by non-native students of English for economics in the course of their studies. We have realised in the process what a challenge this represents in several respects. Firstly, as no precise definition of a hedge exists, nor clear criteria for identification, our choice was bound to be subjective. We tried to offset this risk by comparing different genres and selecting only the most commonly used devices. Secondly, except perhaps for a limited number of cases, it is very difficult to state with certainty that a term or a phrase is to be considered as a hedge. This problem, however, is a wonderful opportunity to insist on the importance of studying hedges in their contexts (Mauranen 1997, Nikula 1997, Widdowson 1998). For this reason, the lists we have drawn (Appendix 3) should only be considered as tentative frames or guidelines, even though some of the items are set phrases.

Experience has shown us that non-native students feel naturally attracted by such readymade phrases which they consider easy to remember and safe to re-use. In the course of this study, we have underlined some of the pitfalls that await a non-native student if he blindly considers any occurrence of one of the listed terms as a hedge. Besides, even when a term does not seem to be questionable as a hedge, it is still impossible to assert whether it was intended as such by its author (Wills 1997, Salager-Meyer 2000), or whether it has been influenced by convention, trend or fashion, in which case it may have been used unconsciously. As a result, it may have lost much of its impact as a hedge. As for the more sophisticated ways of hedging, which we mentioned in our section on grammar and syntax, it is obviously impossible to draw lists as the variety of combinations is infinite. In the case of accumulated hedging devices, one may also wonder whether an overdose may not kill the intended effect, in addition to blurring the message to such a point that reading becomes a process of deciphering.

51 For all these reasons, non-native students must be guided through this thicket of thorny hedges and be given the means to apprehend them. Hedging is inevitable when social interaction takes place. There is no reason to consider that specialised discourse should be immune to the phenomenon. It is therefore essential to initiate newcomers -i.e. nonnative future researchers - to the forms of hedging that prevail in a specific field, genre or discourse community. We hope that the present investigation will convince teachers to devote more time to trying to turn what could be a problem into a resource so that, 
eventually, non-native students of ESP - here English for economics- will be able to introduce more caution in their own discourse and come closer to native-speaker competence.

\section{BIBLIOGRAPHY}

Banks, D. 1995. "There is a cleft in your sentence: Less common clause structures in scientific writing". ASp 7-10, 3-11.

Barro, R. J. and V. Grilli. 1994. European Macroeconomics. London: MacMillan.

Becker, G. S. 1976. The Economic Approach to Human Behavior. Chicago: University of Chicago Press. Bondi-Paganelli, M. "Language Variations across Genres Quantifiers and Worlds of Reference in (and around) Economics Textbooks". ASp, 11/14, 33-53, 1996.

Brown, P. and S. Levinson. 1987. "Universals in language usage: Politeness phenomena". In E. Goody (ed.), Questions and Politeness: Strategies in Social Interaction. Cambridge: Cambridge University Press.

Clemen, G. 1997. "The concept of hedging: Origins, approaches, definitions". In Markkanen R. and H. Schröder, Hedging and Discourse. Approaches to the Analysis of a Pragmatic Phenomenon in Academic Texts. Berlin: Mouton de Gruyter, 115-134.

Couture, B. 1986. "Effective ideation in written text: A functional approach to clarity and exigence”. In Couture B. (ed.), Functional Approaches to Writing: Research Perspectives. Norwood, NJ: Ablex, 69-92.

Dornbusch, R. and S. Fischer. 1988. Macroeconomics. New York: McGraw-Hill.

Dudley-Evans, T. 1994. "Academic texts: The importance of the use and comprehension of hedges". ASp, 5-6, 131-139.

Henderson, W. and A. Hewings. 1987. Reading Economics: How Text Helps or Hinders. British National Bibliography Research Fund.

Hewings, A. 1990. “Aspects of the language of economics textbooks". In Dudley-Evans T. and W. Henderson (eds.), The Language of Economics. The Analysis of Economics Discourse, ELT Documents n ${ }^{\circ}$ 134. London: MEP/British Council, 29-42.

Mauranen, A. 1997. "Hedging in language revisers' hands”. In Markkanen R. and H. Schröder, Hedging and Discourse. Approaches to the Analysis of a Pragmatic Phenomenon in Academic Texts. Berlin: Mouton de Gruyter, 115-134.

Myers, G. 1989. “The pragmatics of politeness in scientific articles”. Applied Linguistics 10, 1-35.

Myers, G. 1992. "Textbooks and the sociology of scientific knowledge". English for Specific Purposes 11, 3-17.

Nikula, S. 1997. "Interlanguage view on hedging". In Markkanen R. and H. Schröder, Hedging and Discourse. Approaches to the Analysis of a Pragmatic Phenomenon in Academic Texts. Berlin: Mouton de Gruyter, 188-208. 
Niskanen, W.A. 1971. Bureaucracy and Representative Government. Chicago: Aldine Publishing Company.

Rounds, P. 1982. Hedging in Written Academic Discourse: Precision and Flexibility. Mimeo: University of Michigan.

Salager-Meyer, F. 1994. "Le discours aigre-doux de la controverse scientifique". ASp 19-22, 29-50. Salager-Meyer, F. 2000. "Procrustes' recipe: Hedging and positivism”. English for Specific Purposes 19/2,175-187.

Samuelson, P. A. and W. D. Nordhaus. 1998. Economics. $16^{\text {th }}$ ed. New York: McGraw-Hill.

Selinker, L. 1979. "On the use of informants in discourse analysis and language for specialized purposes”. Iral 17,189-215.

Skelton, J. 1985. “The care and maintenance of hedges". ELT Journal 42, 37-43.

Swales, J. M. 1990. Genre Analysis. Cambridge: Cambridge University Press.

Tadros, A. 1985. Prediction in Text, ELR Monograph $n^{\circ} 10$. Birmingham: University of Birmingham. Widdowson, H. 1998. "Context, community and authentic language". TESOL Quarterly 32/4,705-716.

Wills, W. 1997. "Hedging in expert-language reviews". In Markkanen R. and H. Schröder (eds.), Hedging and Discourse. Approaches to the Analysis of a Pragmatic Phenomenon in Academic Texts. Berlin: Mouton de Gruyter, 134-150.

\section{APPENDIXES}

\section{Appendix 1}

\section{References for the research articles in our corpus (Journal of EconomicIntegration)}

Anderson, J.E. (1994) “Strategic Lobbying and Antidumping”, 9: 2.

Anwar, S. "Government Spending on Public Goods, International Factor Mobility and Trade", 10: 4

Boisso, D. and M. Ferrantino (1997) "Economic Distance, Cultural Distance, and Openness in International Trade: Empirical Puzzles”, 12: 4.

Dutton, J. (1994) “Welfare-Enhancing Import Subsidies”, 9: 4.

Fischer, R.D. and L. J. Mirman (1994) "Learning about Enforcement: A Model of Dumping", 9: 2.

Hartigan, J. C. (1995) “A Welfare Enhancing Production Subsidy When Consumers Have Economies of Scale in Shopping”, 10: 4.

Karras G. (1997) "Economic Integration and Convergence: Lessons from Asia, Europe and Latin America", 12: 4.

Kehoe, T. (1993) "North American Free Trade", 8: 2.

Kilkenny, M. (1993) "Agricultural Liberalisation in Segmented or Integrated Markets, with Scale Economies", 8: 2.

Kimbrough, K. P. (1995) “Exchange Rate Regimes and the Real Exchange Rate”, 10: 1. 
Lane, P (1996) “Trade Specialisation, Endogenous Innovation and Growth”, 11: 4

Michael, S. M. (1995) “Foreign Capital Inflow with Public Input Production”, 10: 1.

Thompson, H. (1995) “Factor Intensity Versus Factor Substitution in a Specified General Equilibrium Model”, 10: 3.

\section{Appendix 2}

References for the official reports in our corpus

The Federal Reserve Board

- The Federal Reserve's Semi-annual Monetary Policy Report. Testimony of Chairman Alan Greenspan before the Subcommittee on Domestic and International Monetary Policy of the Committee on Banking and Financial Services, U.S. House of Representatives, February 24, 1998.

- International Economic and Financial System. Testimony of Chairman Alan Greenspan before the Committee on Banking and Financial Services, U.S. House of Representatives, September 16, 1998

- An Update on Economic Conditions in the United States. Testimony of Chairman Alan Greenspan before the Joint Economic Committee, U. S. Congress, June 10, 1998.

- The Federal Reserve's Semi-annual Monetary Policy Report. Testimony of Chairman Alan Greenspan before the Committee on Banking, Housing, and Urban Affairs, U.S. Senate, July 21, 1998.

- State of the Economy. Testimony of Chairman Alan Greenspan before the Committee on Ways and Means, U.S. House of Representatives, January 20, 1999.

- The Federal Reserve's Semi-annual Monetary Policy Report. Testimony of Chairman Alan Greenspan before the Committee on Banking, Housing, and Urban Affairs, U.S. Senate, February 23, 1999.

- Monetary Policy and the Economic Outlook. Testimony of Chairman Alan Greenspan before the Joint Economic Committee, U. S. Congress, June 17, 1999.

- The Federal Reserve's Semi-annual Report on Monetary Policy. Testimony of Chairman Alan Greenspan before the Committee on Banking and Financial Services, U.S. House of Representatives, July 22, 1999.

Bank for International Settlements (BIS)

Quarterly Reviews for 1998 and 1999

Appendix 3

Some recurring phrases that may prove helpful for hedging About the hypothetical, theoretical, simplified world

A basic assumption is that ... / A simple example will illustrate...

Analytical convenience suggests that...

Consider an idealised case / situation...

For analytical purposes, / for concreteness, / for convenience, / for ease of understanding, / for simplicity, / assume / imagine / say / suppose / ...

Given our assumptions, ,...

In a hypothetical case, /in our theoretical discussion,/in the theoretical model... 
It is convenient to start with a number of simplifications. / It will simplify our task if...

Let us take a fantastic example: ...

To keep things manageable / simple / workable /, it is convenient to... / we neglect ...

To simplify matters / the analysis / the discussion / the presentation / pretend...

Our earlier simplification / our previous simplified setting / our simple model / allows us to...

Other things (being / held) constant / equal / the same, ...

Simply put, ...

Under certain assumptions, ...

We begin by considering an oversimplified world / we begin with a number of unrealistic assumptions / we use a simplified example / we adopt the convention that...

\section{Bringing evidence, referring to history}

According to a well-known theorem / according to partial data / according to traditional theory, ...

Available data provide evidence of ...

A well-known result / economic theorem states that ...

Examples abound in the economic literature of ...

Everyone recognises that ...

Evidence indicates that .../ suggests that ... / is pervasive ...

History has shown that ... / History is full of examples ...

It is now widely acknowledged that ... / It is often said that ...

Looking at historical trends, the best evidence suggests that ... / The historical record shows that ...

Market observers suggested that ... / Many writers have asserted that ...

Numerous studies confirm that ...

Other sources estimated that ...

Some observers have noted that... / Some of the empirical evidence is consistent with...

There is a remarkable agreement in the literature ... / There is some evidence that...

This analysis is supported by empirical evidence showing that... / This viewpoint is supported by...

\section{INDEX}

Mots-clés: couverture contre le risque, métadiscours, précaution discursive, précaution renforcée, syntaxe

Keywords: grammar, hedge, hedge (fertilised), metadiscourse, risk avoidance, syntax 


\section{AUTHOR}

\section{CATHERINE RESCHE}

Catherine Resche est maître de conférences à l'Université Panthéon-Assas, Paris 2, où elle enseigne l'anglais économique et financier en $3^{\mathrm{e}}$ cycle. Elle fait partie du CERLAC, Centre de recherche en langues et cultures de l'Université Panthéon-Sorbonne, Paris 1.

catherineresche@club-internet.fr 